\title{
Geografías adolescentes y contacto intercultural. Una visión desde el ámbito escolar ${ }^{1}$
}

\section{Miguel Ángel Alegre Canosa}

Universitat Autònoma de Barcelona. Institut de Govern i Polítiques Públiques

08193 Bellaterra (Barcelona). Spain

miguelangel.alegre@uab.cat

\section{Resumen}

Este artículo profundiza en el debate a propósito de la teoría del contacto intercultural. Más específicamente, en él se analizan las formas y los significados de las experiencias de contacto intercultural en el marco de las geografías adolescentes articuladas en el espacio escolar. Dos son los componentes clave de las geografías adolescentes analizados: sus mapas relacionales (redes sociales) establecidos en clase y en el patio, y sus mapas culturales (subculturas) que definen los sentidos de distancia y proximidad entre individuos y grupos adolescentes. Con el objetivo de conocer las posiciones de alumnos inmigrantes y autóctonos en el marco de las relaciones existentes entre ambos mapas, se recogen aquí los resultados de un trabajo etnográfico realizado en un instituto de secundaria situado en un municipio de la provincia de Barcelona. Los resultados de este ejercicio sugieren que las posibilidades de que el contacto intercultural contribuya a la relativización de los prejuicios interculturales mutuamente compartidos, dependen de cuál sea la configuración de las geografías adolescentes de referencia.

Palabras clave: contacto intercultural, geografías adolescentes, escuela, subculturas, redes sociales.

\section{Abstract. Adolescent geographies and intercultural contact. Visions from the school field}

This article deals with the debate regarding the intercultural contact theory. More specifically, it analyses the forms and meanings of intercultural contact experiences in the frame of adolescent geographies which are established in the school space. There are two basic components when looking at the articulations of adolescent geographies in schools: their relational maps (social networks) which are structured in the classroom and the playground, and their cultural maps (subcultures) which define senses of proximity and distance between individuals and groups. In order to assess the positions of immigrant and native students in the frame of the dialectics between both maps, an ethnographic work has been carried out in two secondary schools situated in different cities of the outskirts of Barcelona (Spain). The results suggest that the possibility that experiences of intercultural contact contribute

1. Los contenidos que se desarrollan en este artículo se basan en el trabajo de tesis doctoral realizado por el mismo autor con el título Geografias adolescentes en secundaria: Los posicionamientos de los hijos e hijas de familias de origen inmigrado en los mapas relacionales y culturales articulados en el ámbito escolar (UAB, 2004). 
towards diminishing the significance of mutually shared intercultural prejudices depends on the specific configuration of the adolescent geographies of reference.

Key words: intercultural contact, adolescent geographies, school, subcultures, social networks.

\section{Sumario}

\section{Marco conceptual 4. Resultados empíricos}

2. Hipótesis 5. Conclusión: Geografías adolescentes y contacto intercultural

3. Planteamiento metodológico y trabajo de campo

Bibliografía

La integración, la inserción, la incorporación, la adaptación o la asimilación, sean quienes sean los protagonistas de la acción (jóvenes, adultos, viejos, hombres, mujeres, de aquí, de allá...) son, al fin y al cabo, procesos finalistas, conceptos con implicaciones teleológicas. Integrarse, inserirse dónde. Adaptarse, asimilarse a qué.

Según se defiende aquí, el marco de referencia de los procesos de «integración» de un colectivo concreto de jóvenes (sea cual sea su procedencia) es la especificidad social de la juventud, lo que aquí denominamos geografías juveniles. Y son estas mismas geografías, de naturaleza diversa y dinámica, las que explican las condiciones de posibilidad — así como los significados y las posibles implicaciones- de aquello que aquí centrará nuestra atención: los procesos de contacto intercultural entre adolescentes pertenecientes a adscripciones étnicas diversas.

\section{Marco conceptual}

\subsection{Geografías adolescentes}

Para entender los significados de los procesos de integración de los jóvenes adolescentes hijos e hijas de familias inmigradas, necesitamos comprender cuáles son las reglas de juego propias de estas geografías. Es necesario conocer sus escenarios, sus territorios, sus coordenadas; conocer cuáles son los equipos (que llamaremos «mapas relacionales») con quién se juega, y cuáles son las instrucciones (que llamaremos «mapas culturales») con qué se juega.

\section{Los mapas culturales}

Si partimos de una noción amplia del término cultura, entendida como los códigos a través de los cuales los individuos manejan, construyen y significan su experiencia social (Clarke y otros, 1976), entonces parece claro que las culturas se componen de «mapas de sentido, a través de los cuales el mundo se 
representa inteligible» (Jackson, 1989: 2). Trasladado al terreno que aquí nos ocupa, cabría entonces especificar que los significados de los discursos, las prácticas, los hábitos y los gustos que elaboran los jóvenes adolescentes se entienden en base a unos determinados mapas culturales que actúan como «diccionario", como marco de relevancia, como guía de orientación a la acción y a la experiencia. Sobre esta base, tales mapas definen signos de identificación, marcas simbólicas generadoras de sentimientos y percepciones de distancia (o proximidad) entre los jóvenes (Willis, 1990). Estos signos, estas marcas son las coordenadas de los mapas culturales de la adolescencia ${ }^{2}$.

En el territorio escolar es clara la existencia de un amplio abanico de coordenadas, de variables significativas: la valoración de la utilidad de la institución escolar, la dedicación al estudio, el rendimiento académico, las expectativas académicas, la relación con el profesorado, la relación con el resto de compañeros... También las lógicas propias de los territorios del ocio sitúan toda una serie de variables cardinales específicas: los espacios donde pasar el tiempo, las compañías, los consumos, el gusto musical, las prácticas habituales, la relación con los grupos juveniles fuera del centro educativo... Finalmente, también el escenario familiar dibuja unos mapas orientados según múltiples señales: la importancia otorgada a la socialización familiar, la percepción sobre el control familiar, la valoración de las normativas familiares, el respeto a los padres, la intimidad y la confianza compartidas, los beneficios (materiales o no) esperados, la diferenciación de los roles de padre, madre, hermanos y hermanas...

Todas estas coordenadas, variables, plantean disyuntivas, incertidumbres, dilemas que los jóvenes y las jóvenes adolescentes se ven obligados a afrontar (Billig y otros, 1988). En función de cómo lo hagan, se aproximarán o se distanciarán entre ellos en las denominadas geografias culturales de referencia. Estas geografías culturales, sin embargo, ni son inequívocas ni son fijas. Si bien tienen algo de objetivo, de estructura "cristalizada», el mismo hecho de ser diariamente vividas provoca su constante resignificación, a la vez que no todo joven comparte, en un momento dado, los mismos criterios definitorios.

\section{Los mapas relacionales}

Las geografías adolescentes no se explican completamente atendiendo sólo a sus plasmaciones culturales. Estas geografías están compuestas, también, de mapas de relaciones concretas, de redes sociales de origen diverso (tanto por su composición interna, como en lo relativo a los territorios donde se articulan). Los jóvenes y las jóvenes adolescentes interaccionan con otros jóvenes adolescentes de manera más o menos frecuente, de forma más o menos inten-

2. Así, el modo como aquí utilizaremos la expresión «mapas culturales», como mapas de sentido, es, en buena medida, deudor del concepto "mapas mentales», según éste fue inicialmente utilizado por Kevin Lynch en su libro The image of the city (1960). De acuerdo con este autor, uno de los fundadores de la geografía de la percepción, nuestra relación cotidiana con el medio urbano necesariamente se encuentra mediatizada por las imágenes, los juicios y los prejuicios que acumulamos sobre él. 
sa y afectiva, cristalizando flujos dinámicos de relación de muy diversa índole: grupos estables, agrupaciones esporádicas, relaciones diádicas (de amistad, de pareja, de compañía circunstancial...), de puente entre grupos diferentes, etc. $\mathrm{Ni}$ que decir tiene que los criterios motivadores y/o legitimadores de estas relaciones son, igualmente, múltiples — amistad, interés, aprecio, obligatoriedad, percepción de «semejanza»—. Todo ello hace que quede corta la expresión "grupos de iguales» a la hora de referirnos a estos juegos de interacción. En cambio, es fundamental conocer las morfologías internas de estas redes sociales, ver cómo se estructuran en función de variables diversas: clase social, sexo, nacionalidad, rendimiento académico, estéticas, lengua materna, zona de residencia, escuelas de procedencia, etc.

El análisis de redes (o análisis reticular) ha experimentado, desde finales de los años setenta, un proceso de progresiva institucionalización académica. Ciertamente, una revisión genealógica del concepto y los usos de las redes sociales en el campo de la investigación excede el alcance de este artículo. Buenos textos pasan ya revista a esta cuestión ${ }^{3}$. Quedémonos con unos de sus principales mensajes: cuando el objeto de estudio incumbe procesos de relaciones interpersonales (éste es nuestro caso), una de las premisas básicas del análisis reticular (o de redes) defiende que la estructuración de las redes contribuye a explicar los discursos y las prácticas de los actores interactuantes, así como sus consecuencias.

Sin embargo, y volviendo a nuestro objeto de estudio, cabe decir que la relación entre mapas culturales y mapas relacionales adolescentes es, efectivamente, una relación dialéctica. Es evidente que los entornos o círculos de relación condicionan las miradas de los jóvenes y las jóvenes adolescentes sobre el mundo en que viven y, por tanto, contribuyen a representar y a experimentar las coordenadas y homologías de la adolescencia en uno u otro sentido. Simultáneamente, es también cierto que los adolescentes y las adolescentes tienen margen de autonomía para juntarse con —o separarse de - las personas o grupos con quien sienten (o quieren sentir) más proximidades —o distancias- identitarias. No hace falta señalar que esta consideración complica el modelo; al tiempo que tenerla presente es la única fórmula para llegar a comprender los significados de las dinámicas (y estrategias) de posicionamiento de los jóvenes y las jóvenes de origen inmigrado (y, en general, de todos los jóvenes) en el conjunto de sus geografías de referencia.

\subsection{La teoría del contacto intercultural. Una aproximación crítica}

Desde que fuera principalmente popularizada por G. W. Allport (1954), la teoría del contacto ha servido de base para la realización de una cantidad ingente de estudios e investigaciones — así como de marco de legitimación de cier-

3. Ver, por ejemplo, Scott (1991), Rodríguez (1995), Molina (2001) o Wasserman y Faust (1994). 
tas intervenciones políticas - que, desde perspectivas diversas y a diferentes niveles, se han dirigido a cuestiones conectadas con las relaciones interétnicas básicamente en los países de tradición anglosajona. La fuerza de la hipótesis del contacto radica precisamente en la simplicidad de su mensaje: del contacto entre individuos de diferentes grupos étnicos resulta una reducción del prejuicio entre estos dos grupos, lo cual favorece la creación de actitudes positivas y tolerantes con la alteridad. La hipótesis del contacto sostiene que son las fronteras (físicas y sociales) existentes entre las vidas cotidianas de grupos «étnicamente diferenciados» lo que promueve la ignorancia mutua. Esta ignorancia alimenta imágenes erróneas, reduccionistas y negativas de base irracional (estereotipos) y engendra sentimientos de hostilidad entre los grupos en cuestión, al tiempo que promueve prácticas y discursos de discriminación social y política de los colectivos minorizados. Estas imágenes estereotipadas, origen del racismo y la xenofobia, son oportunamente corregidas cuando estos grupos inician procesos de acercamiento y conocimiento mutuo.

El mismo Allport remarca que, finalmente, las implicaciones del contacto estarán en dependencia de su naturaleza, así como del contexto en que éste se articula. Más específicamente, este autor situaba cuatro condiciones básicas para que, del contacto, se deriven las consecuencias positivas esperadas: 1) igualdad de estatus entre los participantes en el contacto; 2) basado en una actividad cooperativa; 3) existencia de objetivos comunes, y 4) apoyo institucional. A lo largo de los años, autores seguidores de esta perspectiva han ido acordando la importancia de otros dos factores a tener en cuenta: el contacto debe ser personal e implicar cierta intimidad (Brewer y Miller, 1984), y debe dirigirse hacia la creación de lazos de amistad entre grupos (Pettigrew, 1997).

A pesar de que los defensores de la pertinencia de la teoría del contacto se hayan apresurado a refinar su instrumental teórico y analítico en diversas direcciones (Dovidio, Gaertner y Kawakami, 2003), una de sus premisas esenciales ha sido repetidamente puesta en cuestión ${ }^{4}$. Según han concluido, entre otros psicólogos sociales, Hewstone y Brown (1986): no necesariamente de un contacto exitoso entre dos miembros de grupos «étnicamente diferenciados» (es decir, generador de actitudes individuales positivas en el terreno interpersonal) se derivan recategorizaciones grupales igualmente positivas.

4. No nos detendremos en aquellos planteamientos críticos que cuestionan de raíz la teoría del contacto sobre la base de la importancia que esta teoría otorga a los efectos del «prejuicio interétnico». Según estos planteamientos, la teoría obvia una dimensión de primer orden en el abordaje de cualquier componente de las relaciones denominadas «interculturales»: las estructuras sociales, políticas e institucionales en que éstas tienen lugar. No es de extrañar, por tanto, que autores cercanos a posiciones analíticas estructuralistas hayan abogado por abandonar el enfoque que propone la hipótesis del contacto y sustituirlo por uno que conciba la cuestión de las relaciones y las actitudes interétnicas en términos de consecuencias de la formación de unas determinadas relaciones de poder en el marco de unos contextos y unos procesos sociales que determinan posiciones desiguales de los individuos y de los grupos en la estructura social (Connolly, 2000). 
Nos encontramos entonces con la cuestión de la «intimidad». Vemos cómo aquí se defiende la importancia de un contacto expresivo, que se produzca acompañado de procesos de empatía personal (desde la constitución de redes de amistad, al «enamorarse» y salir juntos jóvenes de diferentes adscripciones culturales). Las aportaciones de dos sociólogas, Mary R. Jackman y Marie Crane, han sido especialmente lúcidas a la hora de señalar los límites de tal supuesto (1986). Tras analizar con detenimiento diversos estudios defensores de las implicaciones de la hipótesis del contacto, las autoras concluyen que, de hecho, no es el contacto íntimo el que promueve la superación de los prejuicios interétnicos, sino más bien el establecimiento de múltiples contactos personales (más o menos superficiales, más o menos instrumentales) en contextos cotidianos. Así, Jackman y Crane tratan de demostrar la trascendencia de lo que, para ellas, son las dos características que ha de reunir un contacto auténticamente desenmascarador de estereotipos, dos factores que necesariamente han de ocurrir conjuntamente: proximidad fisica y conexión personal (no necesariamente empática). Más que la intimidad, el factor determinante es la familiaridad con la experiencia intercultural.

Muy en relación con esta cuestión, se ha discutido sobre la fuerza o el alcance de los impactos positivos de los contactos interculturales interpersonales, atendiendo a su capacidad de extenderse en el tiempo y el espacio. Las líneas de crítica que se han desarrollado en esta dirección se basan, pues, en la formulación del siguiente interrogante: ¿cómo asegurar que determinados procesos individuales de relativización de los estereotipos y los prejuicios interétnicos atribuibles al desarrollo de un contacto interpersonal en un determinado espacio (por ejemplo, la escuela) puedan «sobrevivir» y trasladarse, manteniendo los efectos positivos, a otros campos, a otros momentos conformados por reglas, prácticas y discursos diferentes, incluso contradictorios?

En este sentido, lo que se critica de la hipótesis del contacto tiene que ver con las limitadas consecuencias que un posible cambio actitudinal pueda tener sobre la reestructuración en bloque de unos prejuicios cuya disposición sirve para «construir realidad» de maneras diversas, a menudo divergentes, en diferentes situaciones sociales y territorios de socialización; situaciones y territorios que, a su vez, reinforman y reestructuran muy variablemente la disposición de estos prejuicios. Tal argumento puede estirarse y acabar atendiendo al carácter presuntamente fragmentario de las relaciones enmarcadas en los diversos campos de las geografías adolescentes.

En España, la expresión "contacto intercultural» sobre todo ha sido posicionada como ingrediente propio de la noción más amplia de educación intercultural (Juliano, 1996; Terrén, 2001, 2004). Así, el contacto entre individuos o grupos culturalmente diversos sirve a los propósitos de una educación, de una pedagogía que ofrezca la oportunidad de compartir conocimientos de primera mano que ayuden a deshacer incomprensiones consecuencia de un imaginario colectivo a menudo cargado de prejuicios y tópicos (Alegre y Herrera, 2000; Besalú, 2001; Etxeberria, 2002; Carrasco, 2003; Essomba, 2006; García y otros, 2007). La maleabilidad de las culturas así lo permite; la justicia social, así como el mutuo enriquecimiento individual y colectivo, así lo requieren. 
Sin embargo, un análisis profundo centrado en el encaje de los significados (e implicaciones) de las dinámicas de contacto intercultural en el seno de las realidades propias de las relaciones y las subculturas adolescentes sigue siendo, en nuestro país, una asignatura pendiente. El presente artículo pretende contribuir a rellenar este vacío.

\section{Hipótesis}

La postura aquí defendida es que no se pueden anticipar los valores y los significados de las dinámicas de contacto intercultural (o «interétnico»), así como el alcance de sus posibles impactos sin tomar en consideración al contexto social y al marco de significación específicos en que éste tiene lugar. Este necesario ejercicio de contextualización, en nuestro caso, remite a la configuración particular de las reglas de juego de los campos adolescentes específicamente estudiados, en el seno de los cuales se produce y se significa el contacto intercultural. Dicho de otra forma, las posibilidades de éxito (y fracaso) del contacto, a saber, las posibilidades de que el contacto contribuya o no a la relativización de los prejuicios interculturales compartidos, dependen de cual sea la configuración de las geografías adolescentes en cuestión. Y esto es así en tanto que son las geografías adolescentes (sus mapas de significados, sus mapas de relaciones) las que dotan de un sentido u otro, de unos contenidos u otros las experiencias de contacto.

Resiguiendo la división analítica establecida para el concepto "geografías adolescentes», convendría entonces formularse los dos siguientes interrogantes: 1) ¿Cómo interaccionan las distancias y las proximidades asociadas a los posicionamientos significados en las culturas adolescentes con las distancias y las proximidades apoyadas en categorizaciones etnicistas?; 2) ¿Cómo interaccionan las distancias y las proximidades asociadas a los patrones relacionales del conjunto de jóvenes adolescentes en cuestión con las distancias y las proximidades apoyadas en categorizaciones etnicistas?

\section{Planteamiento metodológico y trabajo de campo ${ }^{5}$}

Este trabajo selecciona, como espacio de ejemplificación de las experiencias de posicionamiento cultural y relacional de estos jóvenes adolescentes, el que representa uno de sus campos de juego más significativos: el territorio escolar. Efectivamente, a pesar de las consecuencias de los legítimos intereses de los padres a la hora de escoger centro, pese a las concentraciones artificiales de alumnos de origen inmigrado en determinadas escuelas, a pesar de los itinerarios educativos que puedan establecerse dentro de la escolarización obliga-

5. Se resume aquí la parte del trabajo de campo de la tesis doctoral en que se basa el desarrollo de los contenidos de este artículo. En el marco del trabajo de tesis, se toman como unidades de análisis dos centros de secundaria y dos grupos clase (uno de segundo de ESO y uno de cuarto de ESO) por cada uno de los centros. 
toria, a pesar de las prácticas institucionales de homogeneizar o desdoblar los grupos clase según el rendimiento, a pesar del tratamiento segregador de la adaptación escolar de los jóvenes extranjeros recién llegados, a pesar de todo ello, la escuela mantiene todavía la posibilidad de dar físicamente cabida a la diversidad, pero también de motivar procesos de proximidad entre unos y otros, de unificar intereses, por ejemplo, bajo el pretexto de alcanzar unos objetivos formativos comunes. Es más, al final y en la base de toda posible intervención en el ámbito curricular, pedagógico u organizativo, nos encontramos con las relaciones, las interacciones, las amistades, las enemistades, las aproximaciones, los distanciamientos, los sentimientos, las emociones, las racionalidades, las luchas y las solidaridades de unos jóvenes adolescentes que también en la escuela forman y reforman, en el transcurso de estas experiencias, sus posicionamientos identitarios. En resumen, la escuela no es tan sólo un espacio socializador, sino que representa también un campo de sociabilidad.

\subsection{El instituto y el grupo clase objeto de estudio}

Se trata de un centro público de secundaria donde se escolarizan 450 alumnos, de los cuales 300 son estudiantes de ESO. Actualmente, además de los cuatro cursos de secundaria obligatoria y de los dos de bachillerato, ofrece cinco ciclos formativos, dos de grado medio y tres de grado superior. El instituto se encuentra en una comarca costera de la provincia de Barcelona, en un municipio de unos 110.000 habitantes. Su área de influencia incluye núcleos urbanos y barrios de clase trabajadora, algunos de ellos con elevados porcentajes de población residente de origen extranjero. El total de alumnos de procedencia extranjera escolarizados en este IES (en su mayoría de origen marroquí) en la etapa de la ESO representa cerca de un $40 \%$ del total de estudiantes en esta misma etapa.

Optar por la selección de un grupo clase de cuarto de ESO facilita centrarse en un momento clave de la trayectoria socioeducativa del conjunto del alumnado de secundaria, la de la finalización de los ciclos de escolarización obligatoria. Encontramos, en este momento, uno de los primeros puntos de inflexión (si no el primero) de los itinerarios que los jóvenes pueden seguir en su transición hacia la vida adulta. Es para los jóvenes adolescentes momento de plantearse los beneficios y los costes, tanto de seguir la trayectoria académica reglada, como de abandonarla y sustituirla por la dedicación a otras opciones (trabajo remunerado, trabajo doméstico...).

De entre las tres líneas de cuarto de ESO que ofrece este instituto, la elección final del grupo clase sobre el que cabe basar el trabajo de campo más intensivo ha seguido fundamentalmente dos criterios. En primer lugar, ha convenido fijarse en la composición del alumnado, asegurando la representación de porcentajes significativos de población extranjera. En segundo lugar, ha sido básico buscar la complicidad y la buena disposición del tutor y del equipo docente correspondiente; no en vano se trataba de informar, justificar $y$ permitir mi presencia en el aula durante sus sesiones de clase. 


\subsection{Técnicas de investigación}

Observación directa. A lo largo de todo el periodo de observación, ha sido constante la interacción mantenida con el conjunto de los alumnos, tanto individualmente como con grupos más o menos amplios: charlas, explicaciones, intercambio de impresiones, preguntas y respuestas, bromas, complicidades... Y ha sido así tanto en el marco del aula como, especialmente, en los espacios y momentos de tiempo libre. Del conjunto de equilibrios metodológicos que esta aproximación ha comportado, no puede concluirse que mi «integración» en las dinámicas propias de los chicos y las chicas objeto de estudio haya supuesto una inmersión participativa entre iguales. Es en este sentido que no califico mi ejercicio a este nivel en términos de observación participante. Otra cosa es que ya en el decurso de estas primeras interacciones se hayan establecido relaciones de empatía, confianza y afecto entre el investigador y algunos de los chicos y chicas en cuestión. Concretamente, el ejercicio de observación se ha orientado a cubrir los puntos de atención que se detallan a continuación.

Dinámicas de aula. El investigador ha compartido diariamente, durante dos meses, la totalidad de las horas de clase comunes con el grupo en cuestión. Durante este tiempo, se ha recogido, en un cuaderno de notas, observaciones como: distribución de los alumnos en el aula, frecuencia y motivos de interacción entre compañeros de mesa, frecuencia y motivos de interacción entre alumnos situados distantes en el espacio físico del aula, protagonistas y criterios de intervención "positiva» en las dinámicas docentes (participación en la resolución de problemas, consulta de dudas, voluntarios en la ejecución de determinadas tareas...), protagonistas y criterios de intervención "negativa» en las dinámicas docentes (disrupciones del orden, provocaciones al profesorado, provocaciones manifiestas a los compañeros...), niveles de seguimiento de los ritmos de la docencia (niveles de atención...), etc. Estas observaciones eran anotadas en una matriz de recogida de información diseñada con tal propósito. A partir de dicha información, se ha podido identificar lo que, de ahora en adelante, designaremos como redes clase, cuya representación gráfica (en forma de sociograma) se muestra en la figura $2^{6}$.

Dinámicas de patio. El objetivo ha sido el de captar las pautas que guían tanto la ocupación y la distribución del espacio del patio, como los patrones rela-

6. Aunque como toda representación gráfica reduce complejidades, dicho sociograma nos permite apreciar los patrones relacionales que mantienen cada uno de los alumnos y el sentido y la fuerza de las agrupaciones resultantes. Estas indicaciones gráficas son posibles en tanto que se ha trabajado en base a una matriz de relaciones ponderada y simétrica. Ello significa que el proceso de observación no sólo ha identificado la existencia o inexistencia de relación entre los individuos, sino que también ha otorgado valores numéricos a la intensidad y a la frecuencia de los lazos observados en horas de clase. El mismo procedimiento del programa informático utilizado (la aplicación NetDraw para sociogramas incorporado al programa UCINET V) permite también mostrar en el espacio las distancias y las proximidades relacionales de los nódulos y los círculos sociales en cuestión. 
cionales de los alumnos y las alumnas dentro de sus límites. La recogida de esta información se ha llevado a cabo distribuyendo el tiempo de observación en función de los diferentes espacios que conforman las zonas de recreo del instituto seleccionado (bancos, explanadas, escaleras, rincones, pistas de juego, gimnasio, biblioteca, pasillos...). Ha sido posible, así, detectar "patrones sólidos», tanto en relación con las compañías mantenidas, como en lo referente a la ocupación física de los espacios; patrones, en todo caso, retratados en un período específico de tiempo.

Entrevistas en profundidad. En este caso, el objetivo ha sido el de captar los valores y los significados de las coordenadas que sirven de referencia para la estructuración de los mapas culturales en los que los jóvenes adolescentes de este grupo (autóctonos y de origen extranjero) identifican sus distancias y proximidades. A su vez, ciertas preguntas del guión de entrevistas se han dirigido a corroborar la configuración de las redes dibujadas en la fase de observación. Los criterios de selección de informantes han sido los que se detallan a continuación.

Con el alumnado de origen inmigrado. Se ha entrevistado la práctica totalidad de chicos y chicas de origen extranjero de este grupo clase. El total de entrevistas realizadas: once (dos chicos y nueve chicas), a las que se deben sumar las mantenidas con cuatro alumnos de origen marroquí estudiantes de otros grupos de cuarto de ESO del mismo instituto (dos chicos y dos chicas).

Con el alumnado autóctono. Inicialmente, se diseña la muestra en función de las anotaciones tomadas en la primera fase de observación del trabajo de campo. El primer criterio ha sido, pues, el de entrevistar a aquellos chicos y chicas con posicionamientos culturales manifiestos (prácticas y estéticas), tensionadores de aquellas coordenadas más directamente identificables. A partir de aquí, se ha ido ampliando la muestra en base a las informaciones extraídas de estas primeras entrevistas. El total de entrevistas realizadas: nueve (cuatro chicos y cinco chicas).

\section{Resultados empíricos}

\subsection{Geografias adolescentes de referencia}

Los mapas culturales de referencia

$\mathrm{Al}$ ser los jóvenes preguntados sobre el sentido de sus prácticas, gustos y discursos en cada uno de sus territorios de sociabilidad, suelen confrontarse dos ejes genéricos de posicionamiento cultural: 1) el eje que opone a los llamados «normales» o «normalillos», a los más «extremados» o «transgresores» ${ }^{7}$, y 2 ) el eje que separa a «maduros» de «inmaduros».

7. Todo aquello que pueda decirse alrededor de estas categorías no debería de hacernos perder de vista la relatividad de lo considerado «normal» o «extremado». En la medida en que se hace referencia a la exploración de unos límites normativos más o menos contestables, todo ello 
A un lado del primer eje, se ubican los posicionamientos considerados «extremados», los que se atribuyen a los jóvenes adolescentes que extreman en la experimentación de unos determinados marcos normativos, tanto en el terreno de las coordenadas estéticas (atrevimientos, provocación, innovación en el vestir), como en el terreno de las prácticas y las actitudes (en el ámbito escolar, familiar y, sobre todo, en el de los hábitos del consumo de ocio). Estos posicionamientos se convierten en los que más influencia tienen a la hora de marcar las fronteras y las oposiciones básicas de estas geografías, sobre todo a través de las circulaciones del conocimiento típico. En tanto que posicionamientos visibles y claramente identificables, se convierten en marcadores de estilo y actitud, signos que motivan la atracción o el rechazo, que llaman a posicionarse a favor o en contra. Desde este punto de vista, funcionan como cohesionadores de grupo, bien por identificación, bien por diferenciación.

$\mathrm{Al}$ otro lado del eje, se vinculan en posicionamientos "normalillos» aquellos jóvenes adolescentes que menos experimentan en el ámbito estético (indiferenciación, discreción, valor instrumental en las formas de vestir), así como en el campo actitudinal (cumplimiento responsable de las expectativas familiares y escolares, y distanciamiento respecto a unas prácticas de ocio consideradas "de riesgo»). En la medida en que eluden destacar, llamar la atención, son los posicionamientos que menos poder tienen a la hora de marcar simbólicamente las geografías adolescentes. Con ello no queremos decir que sobre estas homologías no se produzcan agrupamientos de amistad o compañía estables y duradores. Lo que nos interesa destacar es que estos agrupamientos no se configuran sobre la base de una codificación estricta de criterios de estilo o de comportamiento.

Con respecto al segundo de los ejes identificados, cabe decir que el conjunto de los entrevistados construyen unos significados de lo que quiere decir ser «maduro» (y, a la inversa, ser «inmaduro») muy próximos a los propios del imaginario adulto. Genéricamente, son maduros los que piensan y actúan racionalmente, los que tienen las «ideas claras», los que, hagan lo que hagan, no se dejan llevar por las tentaciones de unos estilos de vida hedonistas que les puedan distraer del cumplimiento de unas responsabilidades y obligaciones que marcarán sus caminos por la juventud y, posteriormente, hacia la adultez.

Muchas son las expresiones de estas significaciones, generalmente variables según los signos de inmadurez a los que se esté haciendo referencia. Muy recurrente es, por ejemplo, afirmar que son maduros los que no se preocupan por «tonterías», los que no hacen el «tonto». Y, verdaderamente, «hacer el tonto» puede querer decir muchas cosas: desde interesarse por «chorradas», por temas

acabará dependiendo de dónde cada individuo y cada grupo fije dichos límites y, cuando sea el caso, de cómo se definan las estrategias seguidas para transgredirlos. En adelante, todo aquello identificado en las entrevistas como «normal», "extremado» o "transgresor», debe ser situado en el marco de cómo se significan estas categorías en las geografías culturales específicas del instituto objeto de estudio. 
banales, intrascendentes, hasta hacer "gamberradas». Asimismo, acostumbran a ser vistas como inmaduras las dedicaciones que denotan cierta falta de civismo. Aquí el ejemplo típico es el del mal comportamiento en clase (falta de respeto a los compañeros, al profesorado, disrupciones para "hacerse el gracioso»...). Son, en cualquier caso, referencias más a travesuras que no a actos de manifiesta transgresión. Desde esta perspectiva, es inmaduro aquél que hace tonterías, como los niños pequeños.

Pero no tan sólo son vistos como inmaduros los que mantienen todavía comportamientos infantiles. Es igualmente compartida la opinión que muchos de los que experimentan en terrenos que marcan distancias con la etapa infantil (salir por la noche, mantener relaciones sexuales, tomar drogas, provocar desde el punto de vista estético, etc.), "en el fondo», son también personas inmaduras. Es decir, son «inmaduros» los que pretenden «quemar etapas» antes de tiempo.

En la construcción de homologías en torno al eje formado por las características madurez e inmadurez, entra claramente en juego la variable género. Por regla general, las chicas aparecen como más maduras, tanto desde su propio punto de vista como desde el de la mayoría de chicos. Dejando a un lado posibles explicaciones fisiológicas, es compartido que los chicos maduran más tarde y que ello a menudo les coloca más próximos a posiciones bien de mayor infantilismo, bien de menor control en las prácticas consideradas transgresoras. En cambio, las chicas se autoatribuyen (y se les atribuye) más capacidad para responsabilizarse de lo que hacen o dejan de hacer, siendo su principal campo de transgresión más el de la experimentación estética que el de prácticas extremadas o de riesgo.

Creo interesante clarificar la manera como pueden cruzarse las homologías relacionadas con el eje formado por las características maduros e inmaduros con las homologías tratadas en torno a la dicotomía normalillos y transgresores (figura 1). En cualquier caso, conviene insistir en que los posicionamientos así recogidos responden a los criterios de definición utilizados por los propios informantes. Nos vemos, así, en aquella perspectiva que los antropólogos denominarían emic.

Infantilismo. En efecto, de gran parte de los argumentos de los jóvenes entrevistados se extrae la asociación entre inmadurez e infantilismo. Los adolescentes y las adolescentes más inmaduros son los que "todavía» se comportan y ocupan su tiempo libre "como niños pequeños». Más concretamente, aparecen en este sentido referencias al hecho que estos jóvenes adolescentes, más que vivir intensamente el ocio, lo que hacen es entretenerse jugando; más que mantener actitudes reflexivas frente a sus responsabilidades y obligaciones cotidianas (también escolares), lo que hacen es dedicarse a «molestar» y divertirse haciendo el gamberro.

Experimentación sin control. Pero no tan sólo predomina la asociación entre inmadurez y mantenimiento de prácticas, gustos y discursos infantiles. A menudo, determinados actos de transgresión, más particularmente los vin- 


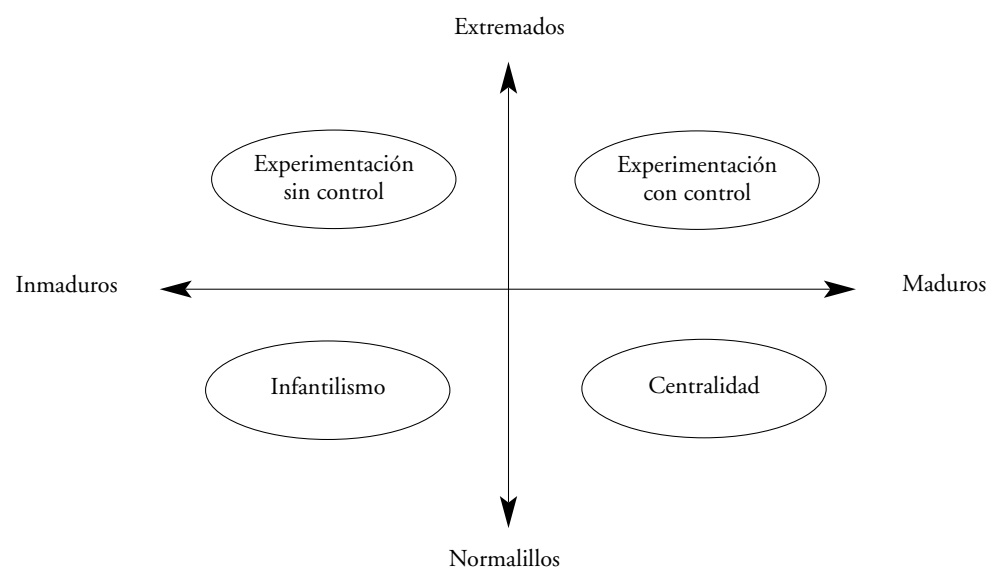

Figura 1. Cruces homológicos.

culados a prácticas y actitudes más extremas, al límite de la pérdida de control, son igualmente evaluados como signos de poca madurez. Lo comentábamos anteriormente: son sobre todo juzgados como inmaduros los que experimentan "en exceso», y lo son tanto desde el punto de vista de los jóvenes más «normalillos», como de los que afirman vivir intensamente la adolescencia en algunos de sus perfiles de provocación normativa, si bien con cierta prudencia y reflexiva moderación. Como ya destacaba, en este punto se sitúan como principal frontera las representaciones sobre los usos y abusos del consumo de drogas.

Experimentación con control. No hay fuente más valiosa de popularidad que el hecho de conseguir combinar vivencias adolescentes extremadas con control y madurez. Una imagen muy precisa al respecto es la que representa la armonía entre saber divertirse y disponer de un buen rendimiento académico.

Centralidad. Nos encontramos aquí con el cruce entre posicionamientos «normalillos» y «maduros». Las homologías que se forman en torno a esta combinación remiten a aquellas situaciones de ausencia de actitudes y comportamientos extremados, por un lado, y conciencia y pleno cumplimiento de las responsabilidades más «serias», por otro. Son, a ojos de padres y profesores, los jóvenes "más centrados», "más correctos». En todo caso, los que responden a estas imágenes están lejos de aproximarse a conductas de riesgo: ni se sienten atraídos, ni, en caso de probar ciertas dosis de experimentación, pierden el sentido del control y de sus auténticas prioridades; unas prioridades enfocadas hacia el mundo adulto, lejos también de los intereses lúdicos del mundo infantil. 


\section{Los mapas relacionales de referencia}

El análisis de redes realizado (ver apartado 3.3) apunta la existencia de tres dinámicas relacionales básicas, dinámicas articuladoras de distancias y proximidades dentro del conjunto de la red social en cuestión. Por un lado, tenemos el agrupamiento formado por Juanjo, Elsa, Alicia, Hugo, Luís y Tina (agrupamiento o clique 1). Una segunda dinámica relacional es la que agrupa a Nelly, Verónica, Débora y David (clique 2). En tercer lugar, aparece claramente visible el conjunto relacional compuesto por las seis chicas marroquíes del grupo, Yamane, Badia, Fathia, Zahida, Ouasila y Rachida, más Violeta, chica argentina (clique 3). Posicionados a medio camino entre estos agrupamientos, se sitúa al resto de alumnos. Entre el segundo y el tercer clique se sitúan dos díadas, Marta-Irene, y Bárbara-Carmen, ésta última en una posición relacional muy central ${ }^{8}$. Próximos al primer clique aparece la díada formada por Nico y Miguel. Muy cerca de ellos encontramos a Alí, que se aproxima también al conjunto de relaciones que articulan las chicas marroquíes, sobre todo a raíz de su conexión con dos de ellas, Yamane y Badia.

\section{Agrupamiento 1}

Desde el punto de vista escolar, todos los alumnos de este grupo han seguido un itinerario académico poco exitoso (con repeticiones de curso o abandonos temporales). Asimismo, todos ellos comparten unos mismos posicionamientos en cuanto a los valores otorgados a la escolarización obligatoria y postobligatoria, y en lo que respecta a las expectativas una vez acabada la ESO: valoran la necesidad de acreditar la educación obligatoria, pero esperan un acceso rápido a sectores poco cualificados del mercado laboral. Si bien dentro del grupo se destacan diferencias internas según los posicionamientos en el eje formado por las características madurez e inmadurez, todos sus compañeros de clase consideran que se trata del grupo más indisciplinado en clase, los que «más la lían», consideración que comparten los mismos protagonistas. También son reconocidas (por ellos y por sus compañeros) sus semejanzas en los terrenos de la transgresión estética y actitudinal. Elsa, chica de la clase a la que todos nombran al ser preguntados sobre aquellos compañeros de clase «que más se preocupan de su imagen», hace referencia también al mantenimiento de prácticas transgresoras como criterio de definición interna (y diferenciación externa): «nosotros hacemos cosas que para el resto son como peligrosas, que no quieren ni verlo, pero que no son peligrosas. Bueno, lo son si te pasas de la raya».

Se trata éste de un agrupamiento que se mantiene íntegramente en las zonas del patio. Se mantiene y se amplía con la participación de algunas chicas de otras clases de cuarto cuyas prácticas informales en los ratos libres, ciertamente conocidas por los demás compañeros, sirven para acentuar el conjunto de las atribuciones que, sobre ellos, se comparte: son de los que, a la hora del

8. La centralidad relacional de Carmen viene dada por el hecho de mantener relaciones con las tres dinámicas de agrupamiento a las que me estoy refiriendo. 


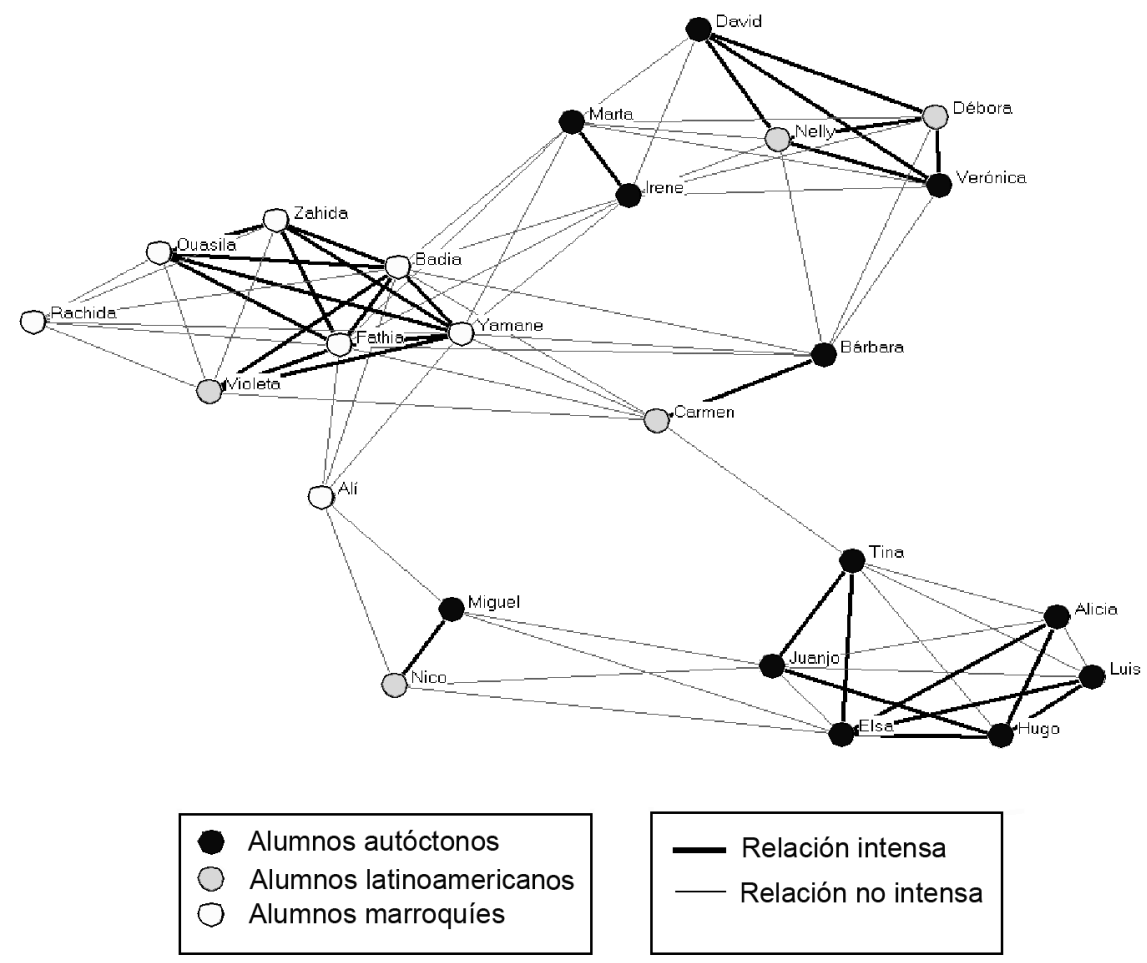

Figura 2. Sociograma del grupo clase.

patio, se esconden por aquellos rincones menos visibles (igualmente reconocidos) y se dedican básicamente a fumar. Se trata, así, de un grupo «marcado simbólicamente».

Agrupamiento 2

Por encima de sus diferencias internas (visibles, por ejemplo, en el terreno estético ${ }^{9}$ ), lo que básicamente identifica el posicionamiento cultural de Nelly, Verónica, Débora y David (así como de las dos díadas que son proporcionalmente próximas: Marta-Irene, y Bárbara-Carmen) es su distanciamiento respecto a las actitudes y a las prácticas más extremadas representadas por los chicos y las chicas del agrupamiento 1. Comparten, por ejemplo, unos mismos discursos sobre los valores y la importancia de la escolarización obligatoria.

9. Verónica, Nelly y Débora, chicas que visten de forma «extremada», se alejan en este campo de David, Irene y Marta, tres alumnos considerados por la mayoría de sus compañeros como los que menos se preocupan de su imagen. 
A excepción de Débora (con un futuro académico más incierto), los demás se preocupan por los estudios y valoran la ESO como una acreditación necesaria, en absoluto suficiente para garantizar un acceso digno al mercado de trabajo. Esperan, así, acabar el cuarto curso y bien pasar a bachillerato o matricularse en algunos ciclos formativos de grado medio. Son también los alumnos más disciplinados en clase (lo dicen ellos, sus compañeros y los profesores). En lo referente al eje formado por las características madurez e inmadurez, se hace efectivo en este caso el principio marcador del género. Las chicas se ven a sí mismas como responsables en la asunción de sus obligaciones "serias», al tiempo que todas ellas sitúan a David como el más inmaduro, más infantil (lo que no le descentra del cumplimiento de sus obligaciones escolares). Nelly, Verónica, Débora, David, Marta e Irene permanecen juntos a la hora del patio, sin ampliar el círculo con otros compañeros de clase o del curso.

Agrupamiento 3

Se trata de un círculo formado por seis chicas marroquíes más una argentina: Yamane (llegó de Tánger con dos años de edad), Badia (nacida en Tánger y llegada con cuatro años de edad), Fathia (llegó de Tetuán con cuatro años), Zahida (procedente de Larraix y llegada con once años), Ouasila (nacida en Tetuán y llegada con catorce años) y Rachida (llegó a los catorce años procedente de Casablanca). La chica argentina se lama Violeta y llegó de Mendoza el curso anterior al correspondiente a la realización del trabajo de campo.

Acabamos de decir que se trata del agrupamiento relacionalmente más distante del clique 1. Esta distancia, sin embargo, no manifiesta únicamente una separación relacional, sino que se vincula con la cristalización de unas marcadas fronteras en los mapas culturales de referencia. El sentido de la oposición es similar al que justifica la separación entre el agrupamiento 1 y el 2: unos representan dinámicas de transgresión (en el aula y fuera de ella) y los demás, de normalidad (dentro y fuera del instituto).

Pero, en el caso que nos atañe, se añaden circunstancias específicas; circunstancias de orden tanto relacional como cultural asociadas a la "cuestión étnica». Nos ocuparemos de ellas más tarde. No obstante, cabe decir que las siete alumnas mantienen su unión en el patio, juntándose con otras chicas de origen marroquí de edades diferentes y con situaciones dispares en cuanto al momento de llegada al Estado y al instituto. Se forma, así, un amplio agrupamiento homogéneo en relación con la adscripción «étnica» y con el sexo y, en esta misma medida, muy visible a los ojos del resto del alumnado.

\subsection{De juicios y prejuicios interculturales}

\section{Mapas culturales y contacto interétnico}

Ciertos valores de las conocidas como ideologias temáticas en torno a la inmigración (Troyna y Hatcher, 1992) se filtran en la configuración de los mapas culturales, de los marcos de relevancia que sirven de «diccionario» para la significación de los actos y las experiencias desarrolladas y vividas por el conjun- 
to de jóvenes adolescentes. Comprender cómo «viajan» estas ideologías temáticas del ámbito de las tipificaciones populares al terreno concreto de las atribuciones "étnicas» que cotidianamente (re)construyen los jóvenes adolescentes, comprender este viaje de lo abstracto a lo específico, requiere nuevamente un ejercicio de contextualización. Conviene relacionar los sentidos de actos y experiencias de discriminación "étnica» con los juicios y los prejuicios que acodan las distancias y las proximidades de las geografías culturales adolescentes. Veamos un par de ejemplos.

Para un chico extranjero (de cualquier origen) ubicado en posiciones adolescentes infantiles acostumbrado a tratar y a compartir espacios con otros chicos autóctonos, con gustos estéticos también compartidos, recibir por parte de alguno de sus amigos autóctonos calificativos "xenófobos», puede perfectamente no tener ningún efecto sobre su posicionamiento relacional. La manera cómo Alí se toma las bromas que sus amigos autóctonos le hacen en relación con su seguimiento del Ramadán es un ejemplo de esta posibilidad:

[...] porque yo aguanto porque no pienso en comer. Hay compañeros que, en el patio, empiezan, «qué Alí, vaya hambre que tienes, ¿eh?», «immm!, chorizo, lo que te gusta». Y yo allá, «iqué cabrones!». El día de la excursión estábamos en el McDonald's, pero yo así [cruzando los brazos]. Y ellos ahí, los cabrones, «mira el queso, ¡qué bueno!». Pero todo en broma, son chavales que me caen muy bien.

En cambio, para una chica de origen extranjero con un posicionamiento relativo caracterizado por actitudes maduras y no extremadas, poco acostumbrada al trato frecuente con chicos y chicas autóctonos, estéticamente desubicada de los códigos de moda y con una situación económica y residencial precaria, oír que algunos de sus compañeros de clase igualmente maduros la descalifican con este tipo de expresiones, puede tener consecuencias significativas sobre sus apuestas relacionales. Seria el caso de Rachida: «a veces me llaman "moro" y eso. Son gente un poco racista. Pero a mí no me molesta, porque no necesito amigos. Tengo amigos y no necesito otros", nos explica.

En definitiva, que un mismo acto o expresión verbal sea interpretado como más o menos racista depende de los posicionamientos relacionales y culturales, tanto de los que los protagonizan como de los que los reciben. Cuanto más grande sea la distancia geográfica entre unos y otros, mayor la probabilidad de significarse en clave racista o xenófoba el acto o expresión en cuestión. Asimismo, es evidente que los impactos de estas percepciones contribuyen, a su vez, a aumentar o no los valores de las distancias «previamente» existentes y los significados de los prejuicios mutuamente compartidos.

Desde la lógica de las condiciones de potencialidad del contacto intercultural, esta constatación equivale a decir que cuantas más distancias se mezclen entre los posicionamientos culturales de los actores interactuantes, más complejo es el recorrido de encuentro y, por tanto, más probabilidades de resultar «infructuosas» las experiencias de contacto. En estas circunstancias, es cuando mejor 
se despliegan las funciones homogeneizadoras de los prejuicios, y, por tanto, cuando mayor es la posibilidad que de un contacto exitoso entre dos miembros de grupos étnicamente diferentes (es decir, generador de actitudes individuales positivas en el terreno interpersonal) no se deriven recategorizaciones grupales positivas. El trabajo de campo realizado permite ilustrar con numerosos ejemplos el funcionamiento de los criterios de excepcionalidad que se derivan: para un joven autóctono, tener amigos marroquíes o ecuatorianos no invalida necesariamente la fuerza de sus prejuicios o estereotipos interculturales. Los amigos son la excepción de la categoría.

Hombre, hay maneras y maneras de tener asco. Yo no soy una racista, porque tengo amigos moros, y los moros buenos me son igual, pero los malos aires... Igual que han venido en patera, que se vayan también. [...] Me incomodan, porque pasas por un sitio o por una calle..., y tienes que ir lo más tapada posible y que no se te vea nada, porque te dan. (Elsa)

$\mathrm{Y}$ si bien funcionan para casos particulares ciertos criterios de excepcionalidad, todos aquellos signos no discordantes con la imagen estereotipada sirven de refuerzo del prejuicio. Es fácil, entonces, recurrir al repertorio de atribuciones popularizadas sobre determinadas «marcas de identidad étnica». Aparecen, así, valoraciones tipificadas sobre determinados rasgos distintivos de la religión musulmana: "[...] pues estando aquí no creo que se tenga que poner el pañuelo. Su religión la tiene que dejar en su país y aquí tiene que integrarse como nosotros» (Alicia), o sobre el peso de las distancias idiomáticas: "[...] yo no voy con ellos porque sé que no me van a hablar en castellano, y se meten contigo hablando en marroquí, y claro no te enteras. Se aprovechan, claro» (Miguel). Una minoría de alumnos autóctonos recurren explícitamente a los clichés clásicos del racismo más intolerante: «son traidores, es que lo llevan en la sangre, y no van a cambiar, son sus genes, que no te puedes fiar", comentaba Hugo.

En todo caso, conviene insistir en el hecho de que, por norma general, este conjunto de atribuciones encuentran apoyo en «bases de realidad» reconstruidas a medida para servir de refuerzo a los significados estereotípicos, a menudo en lo que podríamos denominar leyendas urbanas locales. Es, por ejemplo, lo que se deja oír cuando los estudiantes autóctonos hablan de la «realidad» de uno de los barrios de su cuidad caracterizado por la presencia de un porcentaje elevado de población magrebí residente. Casi todo el mundo tiene alguna historia a explicar sobre sucesos ocurridos en este barrio, generalmente historias no vividas en primera persona, sino relatos de boca-oreja siempre relacionados con el hecho de que en sus calles, en sus portales, en sus parques, se concentran jóvenes de origen marroquí.

No, además que no nos gusta el ambiente que se respira por R. [barrio del municipio]. [...] Pues los marroquíes estos, que van, así, mucho de guay, y que a la mínima que te acerques ya están que si plim. No nos gusta ese ambiente, y nos vamos a callejear a zonas más tranquilas. (Juanjo) 
Hombre, a mí, la verdad, me da un poco de miedo. Me da que con tantos marroquines no se puede ir sola. Me dijo una amiga que a una amiga de ella la violaron unos marroquines. (Tina)

En contraposición, las observaciones de Alí sirven de réplica a las de sus compañeros de clase. Alí reside en el barrio R. y conoce el sentido de sus dinámicas sociales. Una de sus prácticas habituales de ocio consiste en reunirse con amigos suyos en uno de los «famosos» parques de este barrio:

Sí, voy a un parque en la zona más poblada de los moros. En R., el parque del P. [nombre del parque]. Es una zona que está llena de marroquíes, pero hay españolas también. Hay españolas ahí sentadas que las conocemos. Y a veces también están por ahí Badia, Yamane y éstas, que las conoces. Pero muchos marroquíes. Todo el mundo dice, «el parque de los moros», ¿y qué?, no hacemos nada malo. Bueno, a veces la liamos un poco, pero son sólo bromas. No nos pegamos ni $n a$.

La misma Yamane, por ejemplo, explica como, con sus amigas, combinan el paseo por zonas céntricas, con un estarse más estático en el «famoso» parque del P.: «los sábados y domingos o viernes por la tarde, voy a dar vueltas por la riera, o salgo al parque que tenemos por allá, si no se pone de noche temprano, salimos al parque. [...] Charlar de diferentes temas que se nos pasen por la cabeza o jugamos a algo».

Estas «ideologías temáticas» sobre la inmigración, estas «leyendas urbanas» que nos hablan sobre «la manera de ser de los inmigrantes» impregnan los discursos del conjunto de jóvenes autóctonos entrevistados. Pero el análisis de las entrevistas realizadas indica que lo hacen con menos fuerza en el caso de aquellos chicos y chicas que se sitúan más próximos a los posicionamientos culturales de los chicos y las chicas de origen extranjero. En estos casos, parecen relativizarse más fácilmente las definiciones de tales prejuicios. Tengan éstos más o menos amigos de origen extranjero, entonces se dejan oír expresiones del tipo: "[...] nosotras somos muy tolerantes con eso. No somos de, "ah son moros, no vamos con esos". Nos es igual que sean chinos, moros, argentinos» (Marta); o "[...] no por ser marroquíes han de ser malos chavales. Con el R. [alumno marroquí de otra clase], por ejemplo, nos llevamos bien» (Juanjo), etc.

\section{Mapas relacionales y contacto interétnico}

Anteriormente, hemos hablado a propósito de la relación dialéctica existente entre marcaciones relacionales y marcaciones simbólicas. Sea cual sea el orden de los factores, sucede que, una vez cristalizadas estas correspondencias entre mapas relacionales y mapas culturales, son los cliques resultantes los que acaban representando simbólicamente los espacios adolescentes. Volviendo a la cuestión de los significados de los prejuicios interculturales, cuando estas correspondencias de oposiciones acaban englobando el sentido de buena parte de las fobias y las filias del conjunto de jóvenes adolescentes, entonces es fácil 
tomar la "parte» (los conjuntos relacionales concretos) por el «todo» (las atribuciones categóricas generales). Las entrevistas realizadas proporcionan claros ejemplos del funcionamiento de estos mecanismos identificadores.

Por un lado, destacamos la manera como Badia interpreta el significado de la «marca étnica» que separa los posicionamientos geográficos de «marroquíes» y «españoles».

O a lo mejor es que los españoles sois así [ríe]. Mira a la Elsa y éstas. [...] Porque cuando yo veo primero a un español, le veo primero como enemigo que como amigo. Pero si veo a un español que es amigo, me sorprendo mucho, porque nunca me había pasado. Pero para mí es una excepción. Tú imagínate a un español que se hace amigo de un marroquí. También es una excepción. (Badia)

En el siguiente fragmento de diálogo, Yamane recrea la categoría de actitudes «típicamente propias de los españoles» en base a los posicionamientos culturales específicos de los correspondientes cliques «representantes» ${ }^{10}$. También en este caso Yamane identifica excepciones a la regla:

YAMANE: No me importa cómo sea cada uno. Yo he venido aquí, les guste o no, y me quedo. No me importa lo que piensen los demás.

ENTREVISTADOR: ¿Que piensen qué?

Y: Por ejemplo, el Luís, la Elsa, no sé, casi todos. Yo pienso que casi todos los españoles piensan igual... Bueno, no me gusta decir racistas. Pero lo son.

E: ¿Piensas que hay algún español que no piense así?

Y: Bueno la Marta, la Irene y esas me parece que no son así, y algunas más. Pero la mayoría son así, de ese tipo que no les gusta que vengas. Si no les molestara, se juntarían contigo y hablarían contigo. Se harían amigas. Hay algunos que son buenos y nos les importa, pero hay otros que les importa muchísimo. La mayoría son así, e igual se lo quedan para dentro como te lo dicen a la cara.

Realizado este ejercicio, Yamane generalizaba las distancias culturales (oposición de homologías transgresión-normalidad) entre el conjunto de chicas españolas y el conjunto de chicas marroquíes: «ellas salen mucho, y fuman mucho. Sí, eso es diferente, ellas salen mucho y nosotras las marroquinas, en general, no salimos mucho por la noche. Ni tampoco solemos ir de fiesta, sólo por el barrio».

En este caso, el marcado de distancias se opera con respecto a aquellos grupos de chicos y chicas autóctonos más extremados en prácticas y estéticas, aquéllos, a su vez, forman cliques fácilmente identificables (en el aula, en los pasillos, en el patio...). Son éstos los que son, entonces, «usados» como aquéllos que «representan» a los «otros», a los «españoles». La generalización de estas

10. Representantes» en el marco de las geografías culturales específicas de este instituto. 
tipificaciones se encuentra, pues, apoyada en la existencia de marcas relacionales y territoriales.

Desde el lado del clique opuesto, el de los «españoles transgresores», los criterios de identificación recuperan elementos de las ideologías temáticas popularizadas en torno al concepto de "inmigrantes», en general, o de las nociones de "marroquíes», en particular. La presencia de cliques relacionales claramente visibles formados por chicos o chicas de este mismo origen facilita entonces el soporte práctico de estas ideologías. Estos cliques pasan entonces a representar los significados propios de tipificaciones «étnicas» más o menos compartidas. Entre otras cosas, es una cuestión de visibilidad.

Luís: A mí me da igual, porque yo no me junto con ellos. Pero es que este instituto está lleno de moros, que los ves por todas partes, como uno plaga.

HugO: A ver, sí pero..., no sé, hay que se ordenado y cada uno a su país. Los moros, las moras, los negros, las negras y tos. A ver, los negros no, pero los moros son una plaga, igual que los chinos ahora. $\mathrm{Y}$ te das cuenta de cómo son, sólo con verlos.

L: Pero bueno, no son lo mismo los negros y los chinos que los moros. Los moros van más a saco.

$\mathrm{H}$ : Igual que los chinos, que dan asco pero no se meten con nadie. Y no los ves por la calle.

L: Son más disimulados.

H: Igual aquí en M. [nombre del municipio] está la gran mafia china, pero la gente no los ve. Nadie se entera, en cambio los moros están por todos lados, se ven por todos lados y hacen cosas malas.

Las palabras de Hugo y Luis reproducen (de forma radical, de forma extremada) determinados tópicos temáticos sobre la categoría "moro», más concretamente, en referencia a su subcategoría «masculina». Cabe decir que, generalmente, los prejuicios más popularmente compartidos por chicos y chicas en torno al colectivo de origen magrebí, se fundamentan en un estereotipo masculinizado. Acostumbran aquí a combinarse dos niveles de respuesta.

Un primer repertorio de imágenes se dirige a nutrir la categoría de los chicos marroquíes «más infantiles»: «son muy patanes, muy salidos, mal educados, siempre haciendo el gamberro», nos decía Bárbara. Aquí sirven como «base de realidad» las prácticas y gustos «propios» de los grupos de chicos marroquíes alumnos del mismo instituto (por ejemplo, el caso de los chicos que se juntan siempre para jugar a fútbol a la hora del patio).

Un segundo tipo de generalización toma como marca simbólica ciertas adscripciones conductuales asignadas a la «manera de ser» de los chicos marroquíes «más peligrosos», "más transgresores». Según Miguel: «Sí, hubo hace poco una pelea entre moros. Moros entre moros. Y, en una esquina, se les veía con unos machetes así. Están pillados». Este segundo repertorio de prejuicios viene fundamentalmente reforzado por el conocimiento típico acerca de cier- 
tas agrupaciones de chicos marroquíes más mayores, que han dejado los estudios y que acostumbran a circular por ciertos espacios de ocio estigmatizados (recordemos el caso del barrio R.).

El funcionamiento y el alcance de este último principio de generalización llegan a ser reconocidos por los mismos chicos y chicas de origen marroquí. Alí es consciente de ellos y en más de una ocasión ironiza al respecto. Veamos cómo se expresa:

Y cuando, por ejemplo, los marroquíes viven en una zona de ricos, los miran de forma muy mala y piensan mal. Y, por ejemplo, la Elsa siempre me dice que de dónde saco tanto dinero para vivir en ese piso. Es que es un dúplex y así. Y yo siempre le digo, «mi padre trabaja con hachís, ¿vale?». Y se lo ha creído porque piensan eso. Y no es eso, es que mi padre se lo ha currado y ha ahorrado dinero. Están piraos.

En cambio, Saida vive con angustia el hecho de sentirse injustamente posicionada en una categoría que no se corresponde con la realidad de sus prácticas y sus gustos:

Hay cosas que las hacen los chicos grandes, como, por ejemplo, robar, drogas $\mathrm{y}$ todo y se creen que todos somos iguales. Tienen mala vista de nosotros, $\mathrm{y}$ más de los marroquíes que de los inmigrantes todos. Son los marroquíes los que mal visten, roban y todo. Y no es verdad, yo soy marroquina y no soy así, y la mayoría no somos así.

Sea como sea, acostumbra a ser necesario puntualizar en el caso de las chicas marroquíes para que emerjan, en oposición, las correspondientes subtipificaciones categóricas: los chicos más descerebrados y problemáticos, las chicas más introvertidas y pacíficas. En el siguiente fragmento de entrevista, Verónica ordena sus observaciones en esta dirección:

VERÓNICA: Me cabrea porque vienen aquí y, sin hacer nada, se meten con la gente y eso me cabrea. Se meten, o si vas por la calle, te chillan y te empiezan que si estás buena. Si eso me lo dicen otros chicos, españoles o otros, me lo tomo más a gracia, pero marroquíes son tantos, porque, más que nada, no es que te digan "guapa", sino porque te pueden llegar a decir "puta» por ir con pantalón corto o falda. No sé y piensas, "i¿de qué vas, machista asqueroso?!!.

ENTREVISTADOR: ¿Y las chicas marroquíes...?

V: Con las chicas bien, porque son más pacíficas, puede. Al menos, conmigo son pacíficas. Son simpáticas, todo el rato se están riendo. Se ponen a hablar y ya empiezan a reírse. Se ríen con nada. Las ves ahí en los bancos con sus pañuelos. $\mathrm{O}$ en clase les amenazan con una falta o algo, y ya se empiezan a reír.

El punto de apoyo que facilita la reproducción de estas tipificaciones generalizadoras vuelve a ser la visión de cliques «étnicos» claramente identificables 
tanto en el aula como, sobre todo, en los momentos de ocio. Ocurre entonces el mismo efecto generalizador de los correspondientes prejuicios. En la medida en que de entre las chicas marroquíes «destacan» las que llevan pañuelo, son éstas las que (de manera involuntaria) pasan a representar las líneas de marcado simbólico del conjunto. Se trata de una discusión especialmente delicada. El hecho de llevar pañuelo coloca a estas chicas en unas coordenadas muy específicas de los mapas culturales estéticos: visten "extremadas» (en tanto que presentan signos estéticos fuera de la «normalidad» y «visibles» en el contexto de los mapas culturales adolescentes), al tiempo que "discretas» (en tanto que rechazan las formas de ostentación y provocación de la moda estética). En cualquier caso, acaban a menudo siendo consideradas como las principales «representantes» del colectivo de chicas marroquíes.

En relación con esta cuestión, conviene describir un hecho que, a su vez, da cuenta de la trascendencia de la existencia de cliques fácilmente identificables respecto a la reproducción de los tópicos citados. Cuando una chica marroquí no participa de las redes de chicas marroquíes conocidas, sino que comparte círculos de amistad y compañía con chicos y chicas autóctonos (dentro y fuera del aula), entonces acostumbra a ser vista por el resto del alumnado autóctono como "poco marroquí». Es, por ejemplo, el caso de Imane, alumna de otro grupo de cuarto curso de ESO. Así lo comenta Tina:

Hay algunas que no parecen marroquíes, Yamane no parece. Luego hay otra que va a cuarto, que se llama Imane, que no parece nada, nada y que va como nosotras vestida, pantalones de campana, jersey así. Va mucho con la M. [alumna autóctona de otra clase] y éstas. No parece, porque hay algunas que llevan pañuelo, $[. .$.$] y en cambio Violeta pensaba que era marroquí, y es argentina.$ [...] Claro, porque va mucho con ellas [chicas marroquíes], y como tampoco la oigo mucho hablar.

«No parece marroquí», pues. Y el caso es que no necesariamente viste diferente que muchas de las chicas marroquíes que forman grupo con otras chicas del mismo origen, algunas de las cuales llevan pañuelo. De hecho, tal y como lo ilustran las palabras de Tina, llega en ocasiones a darse el caso de identificar como marroquíes chicas que no lo son, por el mero hecho de juntarse frecuentemente y de manera visible con el clique que las «representa». Y lo mismo ocurre en el caso de los chicos marroquíes. Lo que hace que «salgan» de la categoría asignada, lo que hace que dejen de "parecer marroquíes normales» acostumbra a ser el hecho de participar establemente de redes «no guetizadas».

Luís: Ahí en el parque hay un chaval que se llama M. que es moro y tú lo ves que por el nombre es moro, pero no lo parece, y lo ves al chaval un tío gordo y un moro gordo ¿dónde lo has visto tú? Con diecisiete años..., no se ven.

HugO: Y si se ven, son pocos.

L: Este tío sus padres son moros, pero él nació en Barcelona y no parece moro ni nada, es buen chaval, pero quieras o no tiene sangre de moro. 
H: Es que porque se junta con españoles, pero si se juntara con los de su país, también sería un puto moro de mierda.

En definitiva, tanto en el caso de los chicos y las chicas de origen marroquí, como en el de aquellos grupos de chicos y chicas autóctonos más «extremados» y distantes de los posicionamientos culturales de los primeros, impor$\tan$ las representaciones de lo que se ve (y, en ocasiones, lo que no se ve). En este sentido, la existencia de cliques relacionales claramente identificables, tanto en el aula como en los espacios de relación informal, proporciona las bases sobre las que construir o reforzar determinadas tipificaciones.

\section{Conclusión: Geografías adolescentes y contacto intercultural}

¿Es la estructura de las redes la variable que determina la construcción de distancias y proximidades culturales, o es la configuración previa de los posicionamientos culturales distintivos el factor explicativo de la formación de mapas relacionales? Hemos aquí defendido que las relaciones entre ambas variables son de mutuo condicionamiento. Si razonamos desde el punto de vista de los límites y los potenciales de los contactos interculturales, queda claro lo necesario que es situar sus condiciones e implicaciones sobre la base de los efectos de esta dialéctica. Las posibilidades de éxito (y fracaso) del contacto, a saber, las posibilidades que el contacto contribuya o no a la relativización de los prejuicios interculturales mutuamente compartidos, dependen de cuál sea la configuración de las geografías adolescentes en cuestión. No en vano, son las geografías adolescentes (sus mapas de significados, sus mapas de relaciones) las que dotan de un sentido u otro, de unos contenidos u otros, las experiencias de contacto.

He tratado de discernir momentos en que el contacto intercultural toma parte en el contexto de una dirección (mapas culturales y contacto) u otra (mapas relacionales y contacto). En base a los resultados empíricos obtenidos, desde el primer punto de vista, he concluido que: a igual distancia relacional con respecto al alumnado inmigrado, se muestran más próximos a la relativización de prejuicios interculturales aquellos alumnos autóctonos con posicionamientos similares en los mapas culturales de referencia (generalmente, posicionamientos de «normalidad» y no transgresión). En estos casos, aumenta la probabilidad de que surjan experiencias de contacto con consecuencias positivas. Desde el segundo punto de vista: a igual distancia en el seno de los mapas culturales adolescentes, son aquellos alumnos autóctonos más familiarizados con la relación y el conocimiento directo con alumnos inmigrantes (en el centro escolar y en espacios de ocio) los que más fácilmente relativizan algunos de los tópicos de las «ideologías temáticas» al uso.

En todo caso, se deja sentir el peso de las dinámicas colectivas (culturales y relacionales) que tensionan el conjunto de las geografías juveniles. Visto globalmente, es en aquellas situaciones en las que la confrontación de posicionamientos culturales se apoya en la segregación de redes (en el aula, en el 
patio, en espacios de ocio), cuando muy probablemente acaben construyéndose unas distancias geográficas tales que dificulten la producción de contactos interculturales exitosos. Es entonces cuando la experiencia del contacto, por sustentada, personal, cooperativa y legitimada que sea, difícilmente romperá por sí sola las divisiones de unos mapas culturales que van mucho más allá de la estereotipación estrictamente «étnica»; en el mejor de los casos, servirá situaciones de excepcionalidad que «abandonan» unas categorías no puestas en cuestión.

\section{Bibliografía}

Alegre, M. A.; Herrera, D. (2000). Escola, oci i joves d'origen magribi. Barcelona: Diputació de Barcelona. Colección Materials de Joventut; 14.

Allport, G. W. (1954). The Nature of Prejudice. Cambridge, MA: Addison-Wesley. BESALÚ, X. (2001). Diversidad cultural y educación. Madrid: Síntesis.

Billig, M.; Condor, S.; Edwards, D.; Gane, M.; Middleton, D.; Radley, A. (1988). Ideological dilemmas. A social psychology of everyday thinking. Londres: Sage. BREWER, M. B.; Miller, N. (1984). «Beyond the contact hypothesis: Theoretical perspectives on desegregation». En: N. MiLLER; M. B. BREWER (eds.). Groups in contact: The psychology of desegregation. Orlando FL: Academic Press, p. 281-302. CARRASCO, S. (2003). "La escolarización de los hijos e hijas de inmigrantes y de minorías étnico-culturales». Revista de Educación, 330: 99-136.

Clarke, J., Hall, S., JefFerson, T. y RoberTs, B. 1976. Subcultures, cultures and class: a theoretical overview. En: S. Hall y J. HeNDERSON (eds.) Resistance through rituals. Londres: Hutchinson / Centre for Contemporary Studies.

Connolly, P. (2000). «What now for the Contact Hyphotesis? Towards a new Research Agenda». Race, Etnicity and Education, 3(2): 169-193.

Dovidio, J. F.; GaERTNer, S. L.; KaWAKAMI, K. (2003). «Intergroup Contact: The Past, Present, and the Future». Group Processes \& Intergroup Relations, 6 (1): 5-21.

Essomba, M. A. (ed.) (2006). Liderar escuelas interculturales e inclusivas. Equipos directivos y profesorado ante la diversidad cultural y la inmigración. Barcelona: Graó.

ETXEBERria, F. (ed.) (2002). Sociedad multicultural y educación. Donostia: Ibaeta Pedagogía.

GARCÍA, F. J. y otros (2007). «Inmigración extranjera y educación en España: Algunas reflexiones sobre el "alumnado de nueva incorporación”». En: M. A. AlEGRE; J. SUBIRATS (eds.). Educación e inmigración. Nuevos retos para España en una perspectiva comparada. Madrid: Centro de Investigaciones Sociológicas. Colección Academia; 28.

Hewstone, M.; Brown, R. (1986). «Contact is not enough. an inter-group perspective on the "contact hypothesis"». En: M. HewstOnE; R. BROWN (eds.). Contact and Conflict in Intergroup Encounters. Oxford: Basil Blackwell.

JACKMAN, M. R.; CRANE, M. (1986). “"Some of my best friends are black...”. Interracial friendship and whites' racial attitudes». Public Opinion Quarterly, 50(4): 459-486.

JACKSON, P. (1989). Maps of Meaning. An Introduction to Cultural Geography. Londres: Unwin Hyman.

Juliano, D. (1996). «El contacto intercultural: ¿con quién y en qué contexto?». Página Abierta, 61.

LyNCH, K. (1969). The Image of the City. Cambridge: MIT Press. 
MAY, S. (1999). "Critical multiculturalism and cultural difference. Avoiding essentialism. En: S. MAY (ed.). Critical multiculturalism. Londres: Flamer Press.

Molina, J. L. (2001). El análisis de redes sociales. Una introducción. Barcelona: Ediciones Bellaterra.

PeTtigReW, T. F. (1997). "Generalised intergroup contact effects on prejudice». Personality and Social Psychology Bulletin, 23: 173-185.

RodríGueZ, J. A. (1995). Análisis estructural y de redes. Madrid: CIS.

ScotT, J. (1991). Social Network Analisis. A Handbook. Londres: Sage Publications.

TERRÉN, E. (2001). El contacto intercultural en la escuela: la experiencia educativa de gitanos e hijos inmigrantes en el Área Metropolitana de A Coruña. A Coruña: Universidade Da Coruña.

TERRÉN, E. (2004). Incorporación o asimilación: La escuela como espacio de inclusión social. Madrid: Libros de la Catarata.

Troyna, B.; Hatcher, R. (1992). Racism in Children's Lives. Londres: Routledge.

Wasserman, S.; FAust, K. (1994). Social Network Analysis. Cambridge, MA: Cambridge University Press.

WiLLIS, P. (1990). Common Cultures. Symbolic work at play in the everyday cultures of the young. Boulder: Westview Press. 